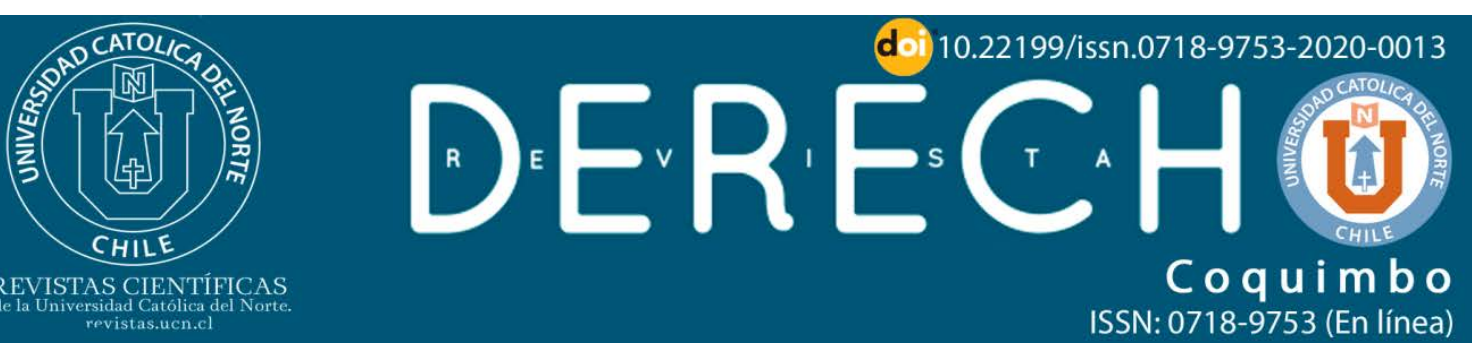

\title{
Las necesidades de la empresa como causa de terminación del contrato de trabajo en el sistema jurídico chileno
}

\section{Company needs as cause for termination of employment contract in the chilean legal system}

\author{
Irene Rojas Miño' (D) https://orcid.org/0000-0001-9955-3550 \\ ${ }^{1}$ Universidad de Talca, Talca, Chile. Doctora en Derecho U. de Valencia, España.

\section{Resumen:}

A partir de las actuales críticas que se plantean a la vigencia de la causa de necesidades de la empresa, este trabajo plantea analizar cómo opera esta causa al interior del sistema de terminación del contrato de trabajo, a fin verificar las perspectivas de reproche: la de las altas exigencias en su configuración y la de su transformación en causa de desahucio empresarial. Para alcanzar dichos objetivos, en este trabajo se analizará el funcionamiento del sistema de terminación del contrato de trabajo y el régimen jurídico de esta causa.

Palabras Clave: Sistema de terminación del contrato; Causa de terminación del contrato; Desahucio empresarial; Causas económicas; Necesidades de la empresa.

\begin{abstract}
:
Starting from the current criticisms that arise to the validity for the cause of company needs, this work proposes to analyze how this cause operates within the termination of employment contract system, in order to verify the reproachable perspectives: high requirements for its configuration and its transformation as a cause of corporate eviction. To achieve these objectives, this work will analyze the functioning of the termination of employment contract system and the legal regime for this cause.

Keywords: Termination of employment contract system; Cause of employment contract termination; Corporate eviction; Economic causes; Company needs
\end{abstract}


Las necesidades de la empresa como causa de terminación del contrato de trabajo...

\section{Introducción}

Desde su reincorporación al sistema de terminación del contrato de trabajo, a través de la Ley Nº 19.010 (1990), la causa de necesidades de la empresa ha planteado un arduo debate en el ámbito de las relaciones laborales en Chile. Así, en la discusión del respectivo proyecto de ley se cuestionó, de una parte, si agregaba la necesaria flexibilidad que requieren las empresas para operar (como señala el Mensaje al Proyecto de Ley del Presidente de la República; "Este proyecto otorga a los trabajadores condiciones adecuadas de protección y estabilidad en sus empleos y preserva la flexibilidad que requieren las empresas para elevar los niveles de inversión, expansión, y modernización", Historia del artículo 10 de la Ley, 1990) y, de la otra, que establecía una causa extremadamente amplia, toda vez que su definición carecía de los supuestos fácticos para su aplicación (En ese sentido; Tapia Guerrero y Walker Errázuriz, 1990, p. 80). Y el debate se mantiene, aunque desde nuevas perspectivas, tanto por las supuestas altas exigencias jurisprudenciales para su configuración y aplicación (Bustos Muñoz, 2013, p. 33), lo que ha llevado a plantear la "ineficacia" de la causa de necesidades de la empresa (Varas Castillo, 2011, p. 93), como por haberse concretado como causa similar a la de desahucio empresarial (Yáñez Monje, 2010).

Precisamente, a partir de las actuales críticas que se plantean a la vigencia de la causa de necesidades de la empresa, este trabajo plantea analizar cómo opera esta causa al interior del sistema de terminación del contrato de trabajo, a fin verificar dichas perspectivas de reproche: el de su transformación en causa de desahucio empresarial, de una parte, y el de las altas exigencias en su configuración, por la otra.

A estos objetivos, junto con conocer la procedencia y definición de esta causa en los sistemas comparados, en este trabajo se analizará el funcionamiento del sistema de terminación del contrato de trabajo y el régimen jurídico de esta causa.

En efecto, a partir de la controversia que plantea su incorporación en cualquier sistema jurídico, para efectuar este análisis se requiere la referencia general de su tratamiento tanto en el Derecho Internacional del Trabajo como en diversos sistemas Comparados ${ }^{1}$, en una perspectiva que considere además de su establecimiento el especial régimen jurídico para que ella opera al interior de cada sistema.

Asimismo, la posible transformación de la causa de necesidades de la empresa en desahucio empresarial atiende a la forma en cómo se aplica dicha causa, lo que requiere analizar si el sistema jurídico vigente permitiría la terminación del contrato

\footnotetext{
${ }^{1}$ Al efecto, dada la necesaria consideración que se debe tener del funcionamiento de esta causa en los sistemas comparados, se ha optado por algunos de nuestro entorno geográfico inmediato, tal cual son los de Argentina y Perú, como de los más alejados que han constituido una referencia en la construcción de nuestro sistema, tal cual son los de España, Francia y Alemania.
} 
de trabajo sin que concurra una causa real, encubriendo de esta manera la sola voluntad del empleador, es decir, el desahucio empresarial².

Tal como, la revisión del régimen jurídico de la causa de necesidades de la empresa se requiere para conocer su contenido y aplicación, junto con evaluar sus niveles de exigencia en su configuración y aplicación. Como se verá, más allá de las normas legales sobre la materia, la definición del régimen jurídico de esta causa ha sido efectuada por los tribunales de justicia, a los que escasamente ha contribuido la doctrina científica - En efecto, la doctrina restringidamente ha estudiado el régimen jurídico de configuración y aplicación de esta causa, efectuando sólo una referencia limitada a tales dimensiones (Rojas Miño, I., 2015, pp. 430-432); Gamonal Contreras y Guidi Moggia (2015, pp. 387-389) e, inclusive, una posición ha negado el aporte de la doctrina jurisprudencial, en cuanto se ha afirmado que son escasos los fallos sobre la materia (Thayer Arteaga y Novoa Fuenzalida (2015, p. 47), más, debe señalarse que esta carencia sólo se planteó en los primeros años de vigencia de esta causa de terminación, lo que tal vez se debió a los efectos de la impugnación de la causal en cuanto en tal caso el trabajador no podía recibir la indemnización por término de contrato -, adquiriendo la doctrina jurisprudencial un rol de primera relevancia en el sistema de fuentes del derecho y reiterándose, además, una constante de los sistemas comparados que registran dicha causa de terminación, en cuanto es dicha doctrina la que define el régimen jurídico de esta causa de terminación del contrato. Al efecto, en este estudio, se efectúa una reconstrucción de dicha doctrina jurisprudencial de los últimos años, emanada principalmente de la Corte Suprema y de las Cortes de Apelaciones.

Este estudio, se organiza en cuatro partes. La primera, comprende una perspectiva general de la causal de necesidades de la empresa, la que incorpora un análisis de las condiciones de incorporación por parte del Derecho Internacional del Trabajo como en sistemas comparados. La segunda, plantea un análisis del sistema de terminación del contrato de trabajo y de la forma en que operan las causas de terminación, particularmente, las de desahucio empresarial y la de necesidades de la empresa. La tercera sección analiza el régimen jurídico de la causa de necesidades de la empresa, tanto en su configuración como en su aplicación. Finalmente, se presentan las principales conclusiones.

\footnotetext{
${ }^{2}$ Se entiende que el desahucio empresarial se configura con la sola decisión empresarial. Rev. derecho (Coquimbo, En línea) 2020, 27: e4424
} 


\section{Perspectiva general de la causa de necesidades de la empresa}

\subsection{La terminación del contrato de trabajo en los diversos sistemas jurí- dicos}

El sistema de terminación del contrato de trabajo, constituye un instituto jurídico de máxima relevancia en toda ordenación de las relaciones laborales, tanto en la perspectiva de definición de política pública como en la de aplicación del derecho. Precisamente, entre las exigencias que se definen para la terminación del contrato de trabajo está el establecimiento de causas. Al efecto, con independencia de lo que establezca un concreto ordenamiento jurídico, se distinguen dos grandes categorías de causas de terminación del contrato de trabajo: las subjetivas, que se fundamentan en la voluntad o en un hecho atribuible a una de la partes del contrato de trabajo, y las objetivas, las cuales se basan en un hecho ajeno a la voluntad de las partes y que inciden en el contrato de trabajo o en la empresa, configurando cualquiera de ellas un antecedente suficiente para poner término al contrato; aunque estas causas presentan diversa naturaleza jurídica y, a la vez, diversas características, según cual sea el sistema jurídico.

En esta categoría de causas objetivas está la de necesidades de la empresa, la que se inserta en la sub-categoría de las causas económicas de terminación del contrato de trabajo, aunque en muchos sistemas se las identifica - la causa de necesidades de la empresa con las causas económicas-, en todo caso, en el sistema chileno es necesario mantener la distinción en cuanto también se inserta otra causa en la categoría de causas económicas, y ésta es la quiebra de la empresa -o sometimiento del empleador a un procedimiento concursal de liquidación, como es denominada con la Ley № 20.720, (2014, art. 350, 2.), incorporado como actual artículo 163 bis del Código del trabajo-. Por consiguiente, la causa de necesidades de la empresa plantea que concurriendo las exigencias y supuestos definidos por el sistema jurídico, el empleador podrá poner término al contrato de trabajo.

\subsection{Las causas económicas o de necesidades de la empresa en los siste- mas comparados}

Independientemente de su denominación, lo cierto es que esta causa ha sido ingresada en diversos sistemas, aunque en ellos se mantiene la discusión respecto de dicha incorporación y del régimen jurídico de su configuración y aplicación, adquiriendo en el tiempo presente una renovada relevancia por los desafíos que presentan los períodos de crisis económica (Muller, 2011).

En una perspectiva global, importan tres alcances para efectos de la definición jurídica de la causa de necesidades de la empresa; estos son, (i) su denominación, (ii) los supuestos que plantea y (iii) las exigencias que se establecen para su aplicación. 
Respecto de su denominación, a nivel de Derecho Internacional, la Organización Internacional del Trabajo (en adelante OIT) le ha otorgado el nombre de "necesidades de la empresa", específicamente de "...necesidades del funcionamiento de la empresa, del establecimiento o del servicio" (Recomendación 119 (1963), y así lo ha establecido en sus instrumentos normativos sobre la materia (Convenio $N^{\circ} 158,1982$; Recomendación 166, 1982), y si bien en ellos no definió su contenido, sí lo ha hecho posteriormente a través de las interpretaciones que ha efectuado de los respectivos preceptos, entendiendo que estos motivos son en general "de índole económica, tecnológica, estructural o similar" (Organización Internacional del Trabajo, 1981, p. 23).

Sin embargo, la mayoría de los diversos sistemas jurídicos que han establecido esta causa económica no le otorgan la denominación dada por la OIT, sino que, a partir del establecimiento de diversos supuestos de carácter económico, tecnológicos o estructurales que operan como causa en dicha terminación del contrato de trabajo, el legislador o el intérprete jurídico han otorgado una denominación específica a la suma de dichos supuestos. Así ha ocurrido en los países de la Unión Europea, en los que, a partir de los diversos supuestos establecidos por el legislador, la doctrina laboralista le otorga la calificación de "causas económicas", tal como sucede en España (Así, lo plantean diversos autores, entre ellos, Desdentado Bonete, 2011, p. 25 y ss.; López López, 2007, pp. 1221-1223) o en Francia (Hernández Bejarano, 2012, pp. 73 y ss.) aunque en este último país la ley la denomina "licenciement pour motif économique..." (Code du Travail, 2008, art. 1233-3).

Dada esta diversidad de denominaciones y considerando que esta causa de terminación del contrato de trabajo responde a "...motivos económicos, tecnológica, estructural o análogos" (Convenio $N^{\circ} 158,1982$, art. 13,1) como ha señalado la OIT, a efectos de análisis de Derecho comparado es posible reconocerla con la denominación común de "causas económicas".

Un segundo aspecto a definir, es el alcance y contenido de esta causa de terminación del contrato de trabajo y los supuestos que comprende. Ciertamente que en ello habrá que atenerse a lo que establezca el respectivo ordenamiento jurídico en razón de lo que establezcan sus diversas fuentes; particularmente, además de la ley, la doctrina jurisprudencial, en cuanto los supuestos legales constituyen en muchos casos conceptos jurídicos indeterminados, por lo que ha sido la jurisprudencia la que ha definido el contenido y alcance de los mismos. Así ha sucedido, a vía de ejemplo, en Francia, en cuanto ha sido la Corte de Casación la que ha precisado los contenidos de las "dificultades económicas" y las "mutaciones tecnológicas" (Hernández Bejarano, 2012, pp. 81-82) o en Alemania, en cuanto se ha desarrollado una jurisprudencia "exhaustiva y muy articulada" (Zachert, 1998, p. 134 ; y López Terrada, y Nores Torres, 2011, p.323). 
En tercer lugar, están las exigencias que se establecen para la aplicación, las que nuevamente dicen relación con lo que disponga el respectivo ordenamiento jurídico. En todo caso, se debe distinguir, de una parte, entre las exigencias generales en la terminación del contrato de trabajo, como pueden ser el preaviso y la procedencia de una indemnización por término de contrato, tal como establece la OIT respecto de la procedencia de causas objetivas (Convenio $N^{\circ} 158,1982$, art. 12) y, de la otra, el cumplimiento de especiales exigencias en el caso de aplicación de la causa económica, tal como son la información y consulta que debe efectuar el empleador a los trabajadores, como también su comunicación a la autoridad administrativa.

Si bien, en la mayoría de los sistemas jurídicos se aplican los principios del Convenio N 158 de 1982 (Organización Internacional del Trabajo, 2011, pp. 1-3), son pocos los países que han ratificado dicho convenio (Ratificación del Convenio $\mathrm{N}^{\circ}$ $158)^{3}$. Además, la regulación sobre causa de necesidades de la empresa tiene diversa aplicación según cuál sea la zona de que se trate.

Respecto de los sistemas comparados, podemos distinguir diversas regiones, importando por ahora los sistemas de nuestro entorno regional, como son los del cono sur de América del Sur (Argentina y Perú) y los de algunos sistemas que han constituido nuestro referente jurídico, tal cual son los de Europa continental (Alemania, España y Francia), aunque los dos grupos de sistemas presentan diferencias.

De una parte, los países del cono sur (Respecto de Perú, véase; Arce Ortiz, 2013. Respecto de Argentina, véase; Díaz y De Salvo, 2013 y Fainguenblat, 2008) han incorporado restringidamente la causa económica. Así, el sistema jurídico peruano sólo la plantea como causa de los despidos colectivos, en efecto, la causa de necesidades empresariales, es decir por motivos económicos, tecnológicos, estructurales o análogos, sólo procede como despido colectivo, en cuanto su aplicación requiere que afecte a más del 10\% del total de trabajadores de la empresa (Arce Ortiz, 2013, 558-559). El sistema argentino (Díaz y De Salvo, 2013; Fainguenblat, 2008), por su parte, la reconduce a específicos supuestos, tal cual son, la causa económica "...por falta o disminución de trabajo no imputable al empleador..." (Ley № 20.744, 1974, art. 268), tecnológica (Ley $\left.\mathrm{N}^{\circ} 24.013,1991\right)$ y organizativas y de mercado (Ley $\mathrm{N}^{\circ} 24.467$, 1995); y si bien respecto de estas causas procede una indemnización de carácter reducida ${ }^{4}$, en los supuestos en que por estas causas el despido supere un número de trabajadores dentro de la empresa, el empleador debe tramitar un procedimiento preventivo de crisis (Ley $\mathrm{N}^{\circ} 24.013,1991$, cap. 6).

De la otra, los países de Europa sí establecen la causa económica como vía expresa de terminación del contrato de trabajo, ya sea en España, Francia o Alemania y, en general, en todos los países europeos. Además, los diversos sistemas con-

\footnotetext{
${ }^{3}$ Sólo 36 de 181 (A la publicación del presente artículo)

${ }^{4}$ Y que corresponde a la mitad de la indemnización general.
} 
templan dicha causa en el ámbito individual, existiendo una regulación especial tanto a nivel de ley como de doctrina jurisprudencial.

En efecto, en Alemania, además de las exigencias establecidas por la jurisprudencia, como es la supresión del puesto de trabajo, la Ley de Protección (que define como causa a "las necesidades urgentes de la empresa, que impidan que el trabajador continúe prestando sus servicios en ella", citada por López Terrada y Nores Torres, 2011 , p. 322) contra el Despido establece dos requisitos para aplicar la causa: primero, que el trabajador no pueda ser ocupado en otro puesto de trabajo dentro de su mismo centro de trabajo o en otro centro de la misma empresa; segundo, que el empleador no haya considerado en la selección del trabajador, o lo haya considerado de forma insuficiente, la antigüedad, las cargas familiares y la edad del trabajador

En España, el despido por causas económicas se configura por las causas previstas por tal motivo para el despido colectivo. Desde la reforma del año 2010, las causas que habilitan los despidos colectivos e individuales son las mismas, "...como idénticas son las finalidades perseguidas para viabilizar los despidos y el control sobre la decisión extintiva."(Blasco Pellicer, 2012, p. 520). En todo caso, la jurisprudencia incorpora varias limitaciones en la definición de los trabajadores que serán despedidos, como es entre otras, que el puesto de trabajo "debe ser sobrante" (Blasco Pellicer, 2012, p. 520).

En Francia, por su parte, la Corte de Casación exige una relación de causalidad entre los hechos invocados, constituida por una serie de antecedentes, como es la necesaria supresión del empleo y la causa aplicada. Así, no se admite esta causa "...cuando la situación de la empresa se debe a la conducta culpable del empleador" (Álvarez del Cuvillo, 2009, p. 272) y se considera que el despido tiene que operar como último medio "...cuando no ha sido posible la recolocación del trabajador en el marco de la empresa o el grupo al que pertenece" (Álvarez del Cuvillo, 2009, p. 272).

\subsection{La especial exigencia en su incorporación: la información y consulta a los trabajadores y las medidas de despido colectivo}

En efecto, tanto la OIT como los sistemas comparados establecen especiales medidas para la aplicación de las causas económicas, las cuales son: la información a los trabajadores, la consulta previa a los representantes de los mismos y las medidas administrativas de autorización previa cuando se configure un despido colectivo.

Así, la OIT a través del Convenio N 158 (1982), establece tres exigencias en la terminación del contrato por motivos económicos, tecnológicos, estructurales o análogos:

Primero, la obligación y correlativo derecho a la información, en cuanto el empleador debe entregar a los representantes de los trabajadores interesados la 
Las necesidades de la empresa como causa de terminación del contrato de trabajo...

información pertinente y en tiempo oportuno "... incluidos los motivos de las terminaciones previstas, el número y categorías de los trabajadores que puedan ser afectados por ellas y el período durante el cual habrían de llevarse a cabo dichas terminaciones". (Convenio $\mathrm{N}^{\circ} 158,1982$, art. 12, 1.a.).

Segundo, la obligación y respectivo derecho de consultas, dado que de conformidad con la legislación y la práctica nacionales, el empleador debe ofrecer a los representantes de los trabajadores interesados, lo antes posible, “...una oportunidad para entablar consultas sobre las medidas que deban adoptarse para evitar o limitar las terminaciones y las medidas para atenuar las consecuencias adversas de todas las terminaciones para los trabajadores afectados, por ejemplo, encontrándoles otros empleos". (Convenio $\mathrm{N}^{\circ} 158,1982$, art. 12, 1.b.).

Tercero, la comunicación a la autoridad competente, en cuanto

...el empleador que prevea terminaciones por motivos económicos, tecnológicos, estructurales o análogos las notificará lo antes posible a la autoridad competente, comunicándole la información pertinente, incluida una constancia por escrito de los motivos de las terminaciones previstas, el número y las categorías de los trabajadores que puedan verse afectados y el período durante el cual habrían de llevarse a cabo dichas terminaciones". Convenio $\mathrm{N}^{\circ} 158,1982$, art. 13, 1).

Por su parte, en los sistemas de nuestro entorno se han definido especiales medidas, en el supuesto de que se configuren despidos colectivos. Así, en Perú la causa de necesidades empresariales, es decir por motivos económicos, tecnológicos estructurales y análogos, sólo procede como despido colectivo, en cuanto debe afectar a más del $10 \%$ del total de trabajadores; debiéndose efectuar un procedimiento que requiere la autorización de la Administración Laboral (Arce Ortiz, 2013, pp. 560561). Mientras que en Argentina se debe tramitar un procedimiento preventivo de crisis, el que más que un procedimiento, es "...una instancia de negociación que tiene como finalidad prevenir conflictos o encontrar soluciones consensuadas" (Díaz y De Salvo, 2013, pp. 350-351).

A nivel de la Unión Europea, se han establecido específicos instrumentos de protección ante los despidos por causas económicas, en los que han influido los procesos de restructuración empresarial, derivados de los procesos de competencia comercial entre las empresas establecidas en el territorio de las Comunidades Europeas (Cruz Villalón, 2012).

En esta materia (para textos bases, puede revisar: Álvarez del Cubillo, 2019; Cruz Villalón, 2012, López López, 2007), la Directiva comunitaria más relevante es la referida al Despido Colectivo, ello sin perjuicio de diversas otras que inciden en esta materia, particularmente las Directivas antidiscriminatorias que precisamente prohíben los despidos discriminatorios. La Directiva sobre despidos colectivos, 98/59 de 
20 de julio de 1998, sostiene que "...interesa reforzar la protección de los trabajadores en caso de despidos colectivos, teniendo en cuenta la necesidad de un desarrollo económico y social equilibrado en la Comunidad;" (Directiva N 98/59/CE, 1998, 2). Al efecto, establece la obligación de consulta a los representantes de los trabajadores y la comunicación a la autoridad laboral, en los supuestos de despidos de un determinado número de trabajadores en el período que se señala. De acuerdo con el art. 1, letra a) de esta Directiva:

...se entenderá por «despidos colectivos» los despidos efectuados por un empresario, por uno o varios motivos no inherentes a la persona de los trabajadores, cuando el número de despidos producidos sea, según la elección efectuada por los Estados miembros:

i) para un período de 30 días:

- al menos igual a 10 en los centros de trabajo que empleen habitualmente más de 20 y menos de 100 trabajadores,

- al menos el 10 \% del número de los trabajadores, en los centros de trabajo que empleen habitualmente como mínimo 100 y menos de 300 trabajadores,

- al menos igual a 30 en los centros de trabajo que empleen habitualmente 300 trabajadores, como mínimo;

ii) o bien, para un período de 90 días, al menos igual a 20, sea cual fuere el número de los trabajadores habitualmente empleados en los centros de trabajo afectados; (Directiva No 98/59/CE, 1998, art. 1.1, a).

La consulta plantea como mínimo “...las posibilidades de evitar o reducir los despidos colectivos y de atenuar sus consecuencias..." (Directiva N 98/59/CE, 1998, art. 2.2), para lo cual el empresario durante el transcurso de las consultas y en tiempo hábil deberá "proporcionarles toda la información pertinente" (Directiva Nº 98/59/CE, 1998, art. 2.3, a).

\section{El sistema de terminación del contrato en Chile}

\subsection{Antecedentes de las causas de necesidades de la empresa y de desahucio empresarial}

Si bien en el actual ordenamiento jurídico sólo está vigente la causa de necesidades de la empresa, toda vez que la de desahucio empresarial se limita a específicas categorías de trabajadores ${ }^{5}$; dadas las críticas al rol que ocuparía la causa de necesidades de la empresa, la interrogante que se plantea es si el ordenamiento jurídico vigente permitiría que la causa de necesidades de la empresa operase también

\footnotetext{
${ }^{5}$ Son tres categorías de trabajadores, cuyo rasgo común es ser depositarios de una especial confianza por parte de sus empleadores, y son: (a) trabajadores que tengan poder para representar al empleador, (b) trabajadores de exclusiva confianza del empleador y (c) los trabajadores de casa particular. 
Las necesidades de la empresa como causa de terminación del contrato de trabajo...

por la sola voluntad del empleador, habiendo reemplazado la causa de desahucio empresarial.

El antecedente cierto, es que ambas causas han estado vigentes en la evolución del sistema de terminación del contrato de trabajo en Chile, aunque en períodos distintos, todas vez que han alternado su vigencia.

En efecto, la causa de necesidades de la empresa fue incorporada a través de la Ley $N^{\circ} 19.010$ (1990). En todo caso, esta causa había sido establecida originalmente con la Ley $\mathrm{N}^{\circ} 16.455$ - que fue conocida como "Ley de estabilidad relativa en el empleo", la que estableció entre otras causas "Las que sean determinadas por las necesidades del funcionamiento de la empresa, establecimiento o servicio," (Ley N 16.455, 1966 , art. 2, n.10) y cuyo contenido y alcances fueron definidos por la jurisprudencia judicial (Romero Guggisberg, 1990; Lecaros Sánchez, 1991) —. Pero esta causa fue suprimida con la normativa de una nueva legislación laboral, específicamente, a través de la Ley $\mathrm{N}^{\circ} 18.372$ (1984) y reincorporada, como se ha señalado, por la citada Ley $\mathrm{N}^{\circ}$ 19.010 (1990), la que la estableció conjuntamente con "...la falta de adecuación laboral o técnica del trabajador" (art. 3); sin embargo esta última causa fue suprimida posteriormente por la Ley $\mathrm{N}^{\circ} 19.759(2001, \mathrm{n} .24, \mathrm{a})$.

Por su parte, la causa de desahucio empresarial —esto es la que opera por la sola voluntad de empleador- fue derogada en 1990, después de doce años de su reincorporación -efectuado por el Decreto Ley $N^{\circ} 2.200$ (1978)-, eliminación que efectuó la reforma laboral de la Ley N 19.010 (1990), la que la mantuvo sólo para específicas categorías de trabajadores.

El antecedente en tal materia, es que la causa de desahucio empresarial sí ha estado vigente en diversos periodos de nuestra historia legislativa. Primero, desde los orígenes del antiguo Código del Trabajo de 1931 hasta el año 1966, en el que fue derogada por la citada Ley $N^{\circ} 16.455$. Después, es restablecida con los textos normativos del régimen militar, a través del Plan Laboral ${ }^{6}$, específicamente por el Decreto Ley $N^{\circ} 2.200$ (1978), el que estableció como efecto de su aplicación una indemnización por término de contrato, la que originalmente fue de un mes de remuneración por un año trabajado y sin límites. Posteriormente, por la Ley $N^{\circ} 18.018$ (1981), dicha indemnización fue disminuida a un límite máximo de cinco meses de remuneración, la que por tres años tuvo un carácter meramente dispositivo (de 1981 a 19847), es decir, el trabajador podía renunciar a ella desde la celebración del contrato. Paralelamente, la indemnización por despido injustificado, es decir el declarado sin concurrencia de causa legal por el tribunal de justicia ante la impugnación del trabajador, era de un monto similar a la del desahucio; además, en el caso de despido injustifica-

\footnotetext{
${ }^{6}$ Así se denomina al conjunto de textos normativos sobre materias laborales, a través de los cuales el régimen militar impuso un nuevo modelo normativo de relaciones laborales.

${ }^{7}$ Si bien este especial carácter de la norma sobre indemnización fue establecido por la Ley $\mathrm{N}^{\circ} 18.018$, posteriormente la Ley $\mathrm{N}^{\circ} 18.372$, de 1984, restablece su carácter imperativo.
} 
do el legislador estableció la "ficción legal" de entender "...que el término del contrato se ha producido por desahucio del empleador en la fecha que se invocó la causal."(Decreto Ley N².200, 1978, art. 19, inc. 1; Código del Trabajo, 1987, art. 162, inc. 1).

A la vez, uno de los últimos textos normativos que integró el Plan Laboral, específicamente la Ley $\mathrm{N}^{\circ} 18.018$ (1981), también derogó las normas que condicionaban el despido colectivo a una previa autorización administrativa. En efecto, las normas sobre despidos colectivos datan del año 1943, con la entrada en vigencia de la Ley $\mathrm{N}^{\circ} 7.747^{8}$, las que rigieron mientras se mantuvo vigente el antiguo modelo normativo del Código del Trabajo de $1931^{9}$ y también en los primeros años de vigencia del Plan Laboral, toda vez que el Decreto Ley Nº 2.200 (1978, art. 7 transitorio), si bien incorporó algunas modificaciones, mantuvo la exigencia de autorización administrativa ante el despido colectivo.

En definitiva, el modelo original de terminación del contrato de trabajo del Plan Laboral, dejó indemne la decisión del empleador de poner término al contrato de trabajo a través del desahucio empresarial, equiparando, además, los efectos del desahucio empresarial con el del despido injustificado, los que en dicho régimen jurídico se limitan al pago de una indemnización, cuya cuantía además es bastante limitada.

En el nuevo sistema democrático ${ }^{10}$, se ha modificado en parte el régimen jurídico de terminación del contrato de trabajo, tal como se ha señalado. En el marco de las primeras reformas laborales al Plan Laboral, cuyo origen son las propuestas del primer gobierno en dicho sistema a partir del año 1990, la modificación del sistema de terminación del contrato de trabajo constituye precisamente el primer proyecto que se debate en el Congreso Nacional, tras el compromiso de fundamentar el término del contrato en una causa objetiva. La discusión generada por la propuesta de reincorporación de la causa de necesidades de la empresa, estuvo referida, por una parte, a la amplitud de dicha causa y la falta de concreción de los supuestos fácticos para su aplicación y, por la otra, a la necesaria flexibilidad que requieren las empresas; constituyendo la primera posición, un anticipo del desafío que enfrentaría la doctrina jurisprudencial referida a definir el contenido y alcance de esta causa. En todo

\footnotetext{
${ }^{8}$ Cuyo origen es un proyecto del entonces Presidente de la República, D. Juan Antonio Ríos, quien, dado el conflicto bélico internacional, propuso medidas especiales y en relación a las relaciones laborales

${ }^{9}$ En síntesis, esta regulación planteaba que el despido colectivo que afectase a más de diez trabajadores requería, en primer lugar, la autorización administrativa previa -de los Ministros de Economía, Fomento y Reconstrucción y de Trabajo y Previsión Social-, en segundo lugar, un aviso previo a los trabajadores afectados y a la Inspección del Trabajo respectiva y, en tercer lugar, en el supuesto que la Administración considerase injustificada la medida, procedía el pago de una indemnización especial -sin perjuicio del "desahucio legal" (es decir, sin perjuicio de la indemnización por término de contrato que habían establecido distintos textos legales), equivalente a quince días de salario por cada año y fracción superior a nueve meses.

${ }^{10}$ El que se inicia en el año 1990, después de diecisiete años de dictadura militar. 
caso, la ley laboral sí estableció el régimen jurídico en otros aspectos, a saber, la procedencia de una indemnización a cargo del empleador, los requisitos de forma y de fondo en dicha terminación del contrato de trabajo, y los efectos jurídicos que plantea el incumplimiento de tales exigencias. $Y$ aunque su régimen jurídico ha tenido algunas modificaciones, éste mantiene sus elementos generales hasta hoy, aunque con posterioridad, diversos textos normativos han incidido en el sistema de terminación del contrato, particularmente a través del aumento de la indemnización por despido injustificado y de la incorporación de una indemnización por lesión a derechos fundamentales (Modificaciones que fueron efectuadas por Ley $\mathrm{N}^{\circ} 19.010,1990$; Ley $\mathrm{N}^{\circ} 19.759,2001$, y Ley $\left.\mathrm{N}^{\circ} 20.087,2006\right)$. En todo caso, el Estado de Chile no ha ratificado las normas internacionales sobre las exigencias para la aplicación de las causas económicas, tal como es el Convenio $N^{\circ} 158$ (1982) de la OIT, y tampoco ha establecido exigencia alguna para los despidos colectivos.

Y la interrogante que en definitiva se plantea, es si el sistema jurídico vigente mantiene en términos generales la sola voluntad empresarial como fundamento de la terminación del contrato de trabajo.

\subsection{El despido, o la terminación del contrato de trabajo por iniciativa del empleador, sus exigencias y sus efectos}

Es cierto que desde la perspectiva formal, el sistema de terminación del contrato de trabajo en Chile es causado. Al efecto, el ordenamiento jurídico establece diversas exigencias a la aplicación de las causas de terminación del contrato y, a la vez, plantea específicos efectos. Dichas exigencias y efectos se definen en razón de la causa o categoría de causas, entre las que está el despido o terminación del contrato por iniciativa del empleador, sin perjuicio de los problemas conceptuales que plantea la expresión "despido", se debe acordar que "despido" corresponde al término de contrato por iniciativa del empleador, cualquiera sea la causa de dicha terminación, y ello sobre la base de lo establecido por el legislador laboral. En efecto, la Ley No 19.631 (1999) amplía la calificación de despido a toda terminación efectuada por iniciativa del empleador, en cuanto expresamente sanciona que "Para proceder al despido de un trabajador por alguna de las causales a que se refieren los incisos precedentes o el artículo anterior..." (Ley № 19.631, n. 1, c) éstas son las causas de terminación por iniciativa del empleador.

En la categoría del despido por el empleador, el ordenamiento jurídico plantea específicas exigencias, algunos de fondo y otras de carácter general, además dicho despido puede ser impugnado ante los tribunales de justicia y en determinados supuestos procede una indemnización por término de contrato de trabajo, distinguiéndose al efecto diversas categorías de indemnizaciones (Rojas Miño, 2013), materias que se analizan a continuación. 
En primer lugar están las exigencias de fondo, en cuanto el despido por iniciativa del empleador requiere cumplir exigencias sin las cuales el despido es nulo - tal como son el pago de cotizaciones de seguridad social, el respectivo desafuero en atención a categorías específicas de trabajadores y el debido respeto a la libertad sindical-, o plantea una sanción superior — como es el despido por lesión a derechos fundamentales-. Ciertamente que estas exigencias constituyen una protección al trabajador por bienes jurídicos superiores, como es la libertad sindical y la vigencia de otros derechos fundamentales, o el resguardo de sus cotizaciones de seguridad social, en un sistema que es mayoritariamente de capitalización individual. Sin embargo, algunas de estas protecciones plantean bajos niveles de eficacia en el objetivo de la tutela de la estabilidad laboral, como es el respecto de esta última institución — despido nulo por no pago de cotizaciones de seguridad social - en cuanto igual comprende la separación del trabajador manteniendo sólo vigente el pago de la remuneración; asimismo, frente a la nulidad del despido por protección de la libertad sindical, en algunos casos se resuelve el término del contrato con derecho a especiales indemnizaciones (León con Zeal Sociedad Concesionaria S.A., 2015).

En segundo término, están las exigencias de forma en el despido. Estas exigencias, están referidas a la comunicación del despido a través de la carta de despido y al contenido de la misma. Al respecto, debe recordarse que el sistema impone a este que debe comunicar por escrito la terminación del contrato de trabajo al trabajador (Además, se deberá enviar copia de tal comunicación a la Inspección del Trabajo respectiva. Código del Trabajo, 2003, art. 162), ya sea personalmente o por carta certificada a su domicilio, en la que debe expresarse la o las causales invocadas y los hechos en que se funda, además de que el aviso debe ser dado con la anticipación definida en atención a la causa acusada, pudiendo en la aplicación de las causas de necesidades de la empresa y de desahucio empresarial pagar una indemnización sustitutiva del aviso previo, la que corresponde a una remuneración de treinta días.

Las consecuencias que tiene el incumplimiento de estas formalidades dependerán de la exigencia en particular, aunque el efecto general es el de la mera configuración de una infracción laboral. Sin embargo, se plantean efectos especiales en dos supuestos: en el caso que no se invoque causal alguna se configuraría un despido injustificado y en el de la carta de despido que no cumple con las exigencias de su contenido.

En tercer lugar, está la exigencia del contenido de "la carta de despido". De acuerdo con las exigencias generales, es la carta de despido la que define la causa aplicada y los hechos que la fundamenta (Código del Trabajo, 2003, art. 162, inc. 1 y $4)$, “...sin que pueda alegar en el juicio hechos distintos como justificativos del despido", tal como señala el Código del Trabajo (2003, art. 454, n. 1), respecto de la audiencia de juicio, configurándose de esta manera una "garantía para el trabajador, 
Las necesidades de la empresa como causa de terminación del contrato de trabajo...

que (...) le permite tener certeza acerca del hecho del despido" (Fernández Cuervo, 2014, p. 79).

Y la discusión se ha planteado con el carácter de dicha exigencia y, correlativamente, con los efectos de su incumplimiento, en cuanto si se trataría sólo de una exigencia formal o constituye una exigencia de fondo. Este debate se planteó principalmente en la jurisprudencia, toda vez que hasta pocos años atrás, los tribunales plantearon que su incumplimiento sólo generaba sanciones administrativas:

...del tenor de los incisos primero, segundo, tercero y octavo del artículo 162 del Código del Trabajo, se advierte que el legislador se ha colocado en la situación que el empleador cometa errores en el aviso enviado al trabajador o, simplemente, lo omita, privando a tales circunstancias, sin embargo, del efecto invalidante referido por los jueces de la instancia, en relación a la terminación del contrato de trabajo, la que mantiene su consecuencia, es decir, la desvinculación entre las partes. (Quezada Marín Raúl Domingo con Distribución, Logística y Servicios Limitada, 2010)

Presentándose así una confrontación entre la tesis de indefensión por incumplimiento y la de los meros efectos administrativos (Fernández Cuervo, 2014).

Sin embargo, la doctrina jurisprudencial actual es clara en la concurrencia de dicha exigencia para la definición de la causa aplicada. Así concluye la Corte Suprema en cuanto debe indicarse en la misiva "...tanto la causal legal como los hechos en que se funda, los que deben ser específicos y no genéricos..." (Marcela Cordero Carvacho con Alo Ventas Limitada, 2016, cons. 3), agregando a continuación:

...que regula cómo debe rendirse la prueba en los juicios sobre despido, señala que debe ofrecerla, en primer lugar, el demandado, quien debe acreditar la veracidad de los hechos imputados en las comunicaciones a que se refieren los incisos 1 y 4 del artículo 162, sin que pueda alegar hechos distintos como justificativos del despido... (Marcela Cordero Carvacho con Alo Ventas Limitada, 2016, cons. 3)

Con el fundamento normativo del mandato del Código del Trabajo en su art. 454, n. $1 ;$ “... lo que confirma que es lo expresado en la carta de despido aquello determina qué hechos deben probarse en la audiencia de juicio, por lo que debe ser suficientemente explícita para dar lugar a la etapa probatoria" (Marcela Cordero Carvacho con Alo Ventas Limitada, 2006, cons. 3), también plantea que:

...así, el trabajador estará en condiciones de impugnar ante el juzgado competente la decisión adoptada por el empleador solicitando que se lo condene al pago de los recargos legales que sean procedentes, lo que se vería entorpecido si desconoce las circunstancias fácticas reales y precisas que aquél tuvo en consideración para poner término a su fuente laboral; dificultad que experimentaría si se concluye que es suficiente que se mencione alguna o algunas de las razones que, a modo de ejemplo y de manera abstracta, se señalan en 
el inciso $1^{\circ}$ del artículo 161 del Código del Trabajo. (Marcela Cordero Carvacho con Alo Ventas Limitada, 2006, cons. 4)

Ciertamente que además del antecedente normativo, esta doctrina se fundamenta en la teoría de la indefensión.

Efectuado un despido, el trabajador tiene el derecho a impugnarlo ante los tribunales de justicia, ya sea porque el despido es nulo, ya sea porque no se configura la causa alegada y se demanda el despido indebido, injustificado o improcedente -al que se denomina, en términos generales, como despido injustificado ${ }^{11}$ — o porque se demanda un despido lesivo de derechos fundamentales.

En los dos últimos casos, la resolución judicial que acoge la respectiva acción - el despido injustificado o el despido lesivo de derecho fundamentales - no invalida el despido, aunque en el supuesto de discriminación, el trabajador tiene derecho a la reincorporación. Al efecto, la resolución sólo establecería el especial efecto contemplado en el ordenamiento jurídico, y que no es otro que el pago de las indemnizaciones que procedan, es decir, la indemnización general por antigüedad del trabajador y la indemnización sanción por el despido injustificado, además de indemnización por despido lesivo de derechos fundamentales en el caso de que así se hubiese demandado $y$, respectivamente, declarado. Ahora, bien, las dos primeras indemnizaciones - la de antigüedad y la de sanción - plantean una exigencia adicional para su procedencia: el requisito de período de vigencia mínimo del contrato de trabajo, y este es de un año (Código del Trabajo, 2003, art. 163, inc. 1).

A la vez, la normativa vigente mantiene la ficción legal que encubre al despido injustificado, en cuanto "...se entenderá que el término del contrato se ha producido por alguna de las causales señaladas en el artículo 161, en contrato de trabajo, a fecha que se invocó la causal..." (Código del Trabajo, 2003, art. 168, inc. 4), es decir, por necesidades de la empresa o por desahucio empresarial.

Finalmente, respecto a las indemnizaciones por término de contrato, y como se ha señalado, con el despido se genera la obligación del empleador de pagar específicas indemnizaciones por término de contrato, las que en conjunto con su monto se definen en razón de la causal aplicada.

Así, la primera indemnización que procede es la de antigüedad, cuyo monto es de treinta días de remuneración por cada año trabajado y fracción superior a seis meses, con un límite máximo de trecientos treinta días de remuneración. Esta indemnización, procede por la aplicación de las causas de necesidades de la empresa y de desahucio empresarial; además, también procede por despido injustificado y por

\footnotetext{
${ }^{11}$ Existe discusión respecto de la exacta denominación, en cuanto la norma laboral, específicamente el Art. 168, inciso $1^{\circ}$, del Código del Trabajo de 2003, que establece la denominación genérica de aplicación "injustificada, indebida o improcedente". No obstante, por razones de unificación de ideas y por motivos de redacción, el despido sin justificación se sintetiza precisamente como "injustificado".
} 
Las necesidades de la empresa como causa de terminación del contrato de trabajo...

despido indirecto, pero en estos últimos ambos casos se requiere declaración judicial.

Una segunda indemnización es la que procede como sanción al empleador, ya sea al haber efectuado un despido injustificado o al haber incumplido sus obligaciones de tal manera que el trabajador ha puesto término al contrato a través del despido indirecto. Esta indemnización, procede conjuntamente con la de antigüedad y su monto se calcula en razón de un porcentaje de esta indemnización, el que a su vez depende del disvalor de la causal imputada (Código del Trabajo, 2003, art. 168, inc. 1). En tal sentido, la relación porcentual menor es la que se atribuye a la causa de necesidades de la empresa, la que solo alcanza un 30\% de la indemnización por antigüedad, en circunstancias que algunas otras pueden alcanzar al 100\%, como establece el Código del Trabajo (2003, art., 168, inc.1), la indemnización referida del Art., 163, del mismo código, es decir la de antigüedad, debe ser aumentada en los porcentajes que se indican.

Una tercera indemnización, es la que procede por despido lesivo a los derechos fundamentales, la que también requiere resolución judicial. Sin embargo, y a diferencia de las indemnizaciones anteriores, ésta última no requiere un período mínimo de vigencia del contrato y su monto, además, es definido por el juez de la causa (De acuerdo con el Código del Trabajo, 2003, art. 489, inc. 3, el que va de un monto de seis a once meses de la última remuneración).

\subsection{La procedencia del despido sin causa bajo el pago de una indemniza- ción}

Dados los antecedentes expuestos, es claro que en el sistema de terminación del contrato de trabajo chileno se impone la decisión empresarial de poner término al contrato, en cuanto dicha terminación opera de igual manera aunque no esté fundada en una causa establecida por la ley, por lo que en definitiva se configura un desahucio empresarial, es decir, la terminación del contrato por la sola voluntad del empleador.

Es cierto que esta conclusión puede relativizarse, en cuanto plantea dos especificaciones. La primera, es que el despido sin causa no procedería en el supuesto de incumplimiento de algunas exigencias de fondo, tal cual son el pago de las cotizaciones de seguridad social y del respeto al fuero laboral, a la libertad sindical y específicos derechos fundamentales. La segunda, es que el despido sin causa presenta un efecto, y este es el pago de una indemnización, siempre que el trabajador accione judicialmente, y cuyo monto dependerá de la causal esgrimida y no acreditada.

Por consiguiente, y salvo en el supuesto de exigencias de fondo, el despido sin causa procede bajo el pago de una indemnización. Y, precisamente, la causa que plantea un menor costo es la de necesidades de la empresa, en cuanto esta sólo su- 
pone un aumento de un $30 \%$ por sobre la indemnización de antigüedad, mientras que las otras causas implican un aumento que va del 50\% al 100\%; además, de que la aplicación de algunas de estas últimas causas podrían constituir falta o, inclusive, una injuria en contra del trabajador.

De esta manera, podría concluirse que es la causa de necesidades de la empresa la que plantea un menor costo en el supuesto de encubrir un desahucio empresarial, lo que permitiría presumir su amplia aplicación en el sistema de relaciones laborales. Tal presunción se ve corroborada con los datos disponibles de la Encuesta Laboral (Dirección del Trabajo, 2009; Dirección del Trabajo, 2012), los que en esta materia son de ocho años atras ${ }^{12}$ pues posteriormente tales no han sido informados; toda vez que descontados los supuestos referidos a terminaciones de contratos temporales, esta causa alcanza una aplicación de un 17,5\%. En todo caso, sería necesario para dar cuenta del impacto de la aplicación de esta causa de necesidades de la empresa en el sistema de terminación del contrato de trabajo, en particular, y en el de relaciones laborales, en general, un estudio que permita su medición tanto en sede administrativa, como es a través de los reclamos ante las Inspecciones del Trabajo, como en sede judicial, dado por la impugnaciones planteadas a través del despido injustificado.

\section{El régimen jurídico de la causa de necesidades de la empresa}

El régimen jurídico de las necesidades de la empresa, como causa de terminación del contrato de trabajo en el sistema jurídico chileno, presenta tres materias de análisis: su configuración, las exigencias en su concreta aplicación y los efectos jurídicos de dicha aplicación. Si bien estos tres aspectos están definidos por la norma legal, en la definición de su actual régimen jurídico ha intervenido la doctrina jurisprudencial.

Al efecto, se hace necesario distinguir estas tres materias de análisis.

\subsection{La configuración de esta causa}

Si bien es la ley la que establece dicha causa, su definición es de carácter general, en lo pertinente, el Código del Trabajo (2003) establece:

... el empleador podrá poner término al contrato de trabajo invocando como causal las necesidades de la empresa, establecimiento o servicio, tales como las derivadas de la racionalización o modernización de los mismos, bajas en la productividad, cambios en las condiciones del mercado o de la eco-

\footnotetext{
${ }^{12}$ La Encuesta Laboral, es una encuesta periódica efectuada por la Dirección del Trabajo, la que presenta una serie trianual que data de 1998. Sin embargo debemos remitirnos a las de los años 2011 y 2008, pues la de 2014 no comprende tal información.
} 
Las necesidades de la empresa como causa de terminación del contrato de trabajo...

nomía, que hagan necesaria la separación de uno o más trabajadores. (art. 161)

Y no presenta los elementos de su configuración, lo que ha sido reconocido por la doctrina científica desde su incorporación al ordenamiento jurídico. Al efecto, la doctrina jurisprudencial ha sido esencial en la definición del régimen jurídico de la conformación de esta causa. Así, la Corte Suprema ha declarado respecto de la causa de necesidades de la empresa:

...al consagrar la causal invocada para el término de la relación laboral en análisis, el legislador ha pretendido su definición en términos que distan de ser concluyentes, exigiendo de esta manera que sea el intérprete judicial quien precise su sentido y le asigne el tenido en cuenta en su establecimiento. (Montoya Ogalde Victor y otro con Asociación Chilena de Seguridad Social, 2009, cons. 10)

Consiguientemente, la Corte Suprema ha establecido las bases de la doctrina jurisprudencial, sujetando la configuración de la causa de necesidades de la empresa a la concurrencia de tres exigencias que emanan del mismo precepto legal: que la necesidad se funde en un supuesto técnico o económico, que la necesidad sea de sea de carácter objetivo y que haya una relación causal entre ésta y la necesaria separación de uno o más trabajadores, esta doctrina se plantea en Montoya Ogalde Victor y otro con Asociación Chilena de Seguridad Social, (2009, p. 10), y es reiterada en sentencias posteriores: María Palomo Fuentes y otros con Fundación Nacional del Comercio para la Educación (2015) y Juan Pérez Campo con Latam Airlines Group S.A., (2015).

La primera exigencia, alude a un supuesto que se funde en un elemento de carácter técnico o económico. El elemento técnico se refiere "... a rasgos estructurales de instalación de la empresa, que provocan cambios en la mecánica funcional de la misma". (Montoya Ogalde Victor y otro con Asociación Chilena de Seguridad Social, 2009, cons. 11), mientras que el aspecto económico, importa en general "...la existencia de un deterioro en las condiciones económicas de aquella que haga inseguro su funcionamiento" (Montoya Ogalde Victor y otro con Asociación Chilena de Seguridad Social, 2009, cons. 11). Además, el grueso de la jurisprudencia plantea que el supuesto debe ser de carácter grave, en cuanto debe relacionarse "... con circunstancias graves 0 irremediables en que se encuentra el empleador...." (Ávila y otra con Fundación Educacional Padre Alberto Hurtado, 2014, inc. 5), y, además, debe ser de carácter "permanente" (Hormazábal con Comercial Kaufmann S.A., 2015).

La segunda exigencia se refiere a la causa objetiva. En efecto, el supuesto debe constituir una causa objetiva, por lo que se requiere que sea ajena a la conducta contractual o personal del trabajador y de la mera voluntad del empleador, exigiendo en todo caso de "...la concurrencia de hechos o circunstancias que la hagan procedente" (Montoya Ogalde Victor y otro con Asociación Chilena de Seguridad Social, 2009, cons. 12); tal como ha sucedido con la restructuración definida por una crisis (Claudia 
Alejandra Fernández Pino con Empresas La Polar S.A., 2016) o el cambio de situación de la empresa por la pérdida de sus más relevantes clientes (Gajardo con Market Line Chile S.A, 2015).

Ciertamente que, en todo caso, se requiere la respectiva acreditación, así

...sea que se trate de situaciones que fuercen procesos de modernización o racionalización derivados ambos del funcionamiento de la empresa o de acontecimientos de tipo económico, como son las bajas en la productividad o cambios en las condiciones del mercado, deben todos ellos ser probados en virtud de la carga procesal que la invocación del motivo de exoneración conlleva. (Juan Pérez Campo con Latam Airlines Group S.A., 2015, cons. 10)

Al efecto, se ha discutido la conformación de esta segunda exigencia en los supuestos de modernización y reestructuración de la empresa. Si bien la causa se configura "... de hechos graves de naturaleza económica que se imponen en forma exógena a una administración diligente de la empleadora" (María Isabel Treuna Treuna con Ilustre Municipalidad de Los Ángeles, 2007, cons. 7), se excluyen los procesos técnicos definidos por el mismo empleador, particularmente los de reestructuración, cuando los mismos no responden a causas externas (Correa con Caja de Compensación de Asignación Familiar de los Andes, 2016. En sentido similar, entre otras; Aladino Póntigo Mancuan y otros con Lan Cargo S.A., 2015; Cortes Bordones Jorge con AMECO Chile S.A 2014).

Así, la Corte Suprema ha exigido que "... el costo de la decisión de transformarse, fusionarse (...) no puede ser traspasado al dependiente..." (Montoya Ogalde Victor y otro con Asociación Chilena de Seguridad Social, 2009, cons. 14; Tal cual es el supuesto, a vía de ejemplo de la sentencia Juan Pérez Campo con Latam Airlines Group S.A. 2015). Y el fundamento de esta doctrina es claro: la causa de necesidades de la empresa es independiente de la voluntad del empleador:

...el legislador laboral protege la estabilidad en el empleo y la mantención de las fuentes laborales, siendo de carga del empleador la indemnización de sus trabajadores con los incrementos que al efecto dispone la ley, siempre que la empresa no se encuentre en la necesidad de prescindir de sus empleados por una situación externa e independiente de ella, sino que la misma ha sido generada por su decisión libre, en pro de la optimización de sus recursos y funcionamiento, decisión legitima que la ley no objeta pero cuyas consecuencias deben ser asumidas por el titular de la misma.(Montoya Ogalde Victor y otro con Asociación Chilena de Seguridad Social, 2009, cons. 14)

Finalmente, la tercera exigencia plantea que el supuesto indicado debe hacer necesaria la separación de uno o más trabajadores. Si bien la doctrina de la Corte Suprema no ha explicitado este requisito, sí lo ha hecho la de las Cortes de Apelaciones, la que ha afirmado que "... el carácter de necesario del despido es un requisito sine qua non de la causa alegada" (Ávila y otra con Fundación Educacional Padre Alberto 
Las necesidades de la empresa como causa de terminación del contrato de trabajo...

Hurtado, 2014, inc. 5.); por consiguiente, se requiere una relación causal entre el supuesto indicado y la separación de uno o más trabajadores.

En la aplicación de esta última exigencia, se presentan dos debates: la definición de los concretos trabajadores que serán despedidos, y la procedencia de reemplazo de los trabajadores despedidos.

Respecto del primer aspecto, la definición de los concretos trabajadores a los que se aplica la causal, en cuanto el despido debe ser "... la consecuencia necesaria e indispensable" (Ramos con Veloso, 2017, cons. 6) del supuesto que configura la causa de necesidades de la empresa, cuestionándose de esta manera la falta de criterios objetivos en la determinación de los trabajadores que son despedidos (Rybertt Thennet Mónica con Corporación de Televisión de la Pontificia Universidad Católica de Chile, 2008).

En cuanto a la procedencia del reemplazo posterior de los trabajadores que han sido despedidos, éste ha sido un tema debatido en la doctrina jurisprudencial. Aunque se ha admitido en un supuesto de reestructuración de empresa (Alba Rita Maldonado Hernández contra Empresa de Correos, 2005), mayoritariamente se ha rechazado la configuración de esta causa de necesidades de la empresa en el supuesto de reemplazo en las funciones del trabajador despedido en cuanto "...no existió en la realidad ningún hecho objetivo fundante de aquella decisión, o lo que es lo mismo, no tuvo lugar ningún imperativo técnico o económico de la empresa que hiciere necesaria la separación del actor..." (Rodrigo Mauricio Polo Ahern con Nova Austral S.A., 2017, cons. 8).

\subsection{La exigencia de la carta de despido y de su contenido en la aplicación de esta causal}

Como se ha indicado, la carta despido debe contener tanto la causal legal invocada como los hechos en que se funda, los que deben ser específicos y no genéri$\cos ^{13}$. Pues bien, tratándose de la causa de necesidades se exige una mayor justificación, en cuanto como señala la Corte Suprema: "...se debe indicar en qué consiste el motivo que hace que sea ineludible disponer la separación del trabajador y, además, de la descripción o relación de los hechos debe surgir la necesidad de adoptarla" (Marcela Cordero Carvacho con Alo Ventas Limitada, 2016, cons. 3). Por consiguiente, se requiere la explicitación detallada de los hechos que configuran el supuesto indicado y la necesaria separación del trabajador, exigencia que en tribunales se ha debatido principalmente respecto del fundamento de la reestructuración empresarial. Al respecto, la doctrina vigente sostiene la necesaria explicitación de los fundamentos de hecho que derivan en la reestructuración, y la forma en que la racionalización de recursos desemboca en la necesidad de separación del trabajador afectada por el despido

\footnotetext{
${ }^{13}$ Al efecto, véase, Sección 2.2.
} 
(Mariela Contreras Lobos con Ilustre Municipalidad de La Granja, 2017; En sentido similar, y por todas, Pamela Montalba Cancino con Fundación Consejo de Defensa del Niño, 2017; Fuentes con Inmobiliaria Parque y Jardines del Sendero S.A, 2010). No obstante, años atrás se ha sostenido que no se requiere de detalles pormenorizados de los hechos que fundamentan dicha causa y de las medidas adoptadas en el proceso de racionalización. En cuanto que acoge las tesis de la sentencia del Tribunal:

...el sentenciador se hace cargo del reclamo del demandante, señalando que en concepto de la sentenciadora, la carta de despido señala a grandes rasgos los motivos de la reestructuración y modernización, pero no es necesario detallar minuciosamente cuáles son las medidas que se están implementando ya que la situación del rubro vitivinícola es materia de debate público... (Morales con Viña San Rafael S.A, 2011, cons 2)

Concluyendo en el Considerando Tercero:

Que de la relación efectuada precedentemente, se aprecia que la carta de despido cumple con las exigencias de señalar los motivos que justifican la causal, hechos que a su vez, justificó en juicio con los medios de prueba incorporados... (Morales con Viña San Rafael S.A, 2011, cons 3)

\subsection{Los efectos de la aplicación de la causa de necesidades de la empresa}

El despido por la causa de necesidades de la empresa, como cualquier otra causa, pone término al contrato de trabajo, salvo que dicho acto sea nulo. Fuera de este efecto, el régimen jurídico actualmente vigente plantea otras consecuencias en la aplicación de esta causal: (a) la obligación de pagar una indemnización y la configuración de una oferta de pago irrevocable de la misma. (b) las que se generan en el supuesto de acogerse la impugnación judicial por tal causa, a saber, su cambio de calificación y la eliminación de la imputación a la indemnización de los aportes que hubiese hecho el empleador al seguro de cesantía. Cada uno de estas secuelas, ha originado diversos problemas interpretativos.

\subsubsection{La obligación de pagar una indemnización y la configuración de una ofer- ta de pago irrevocable}

Como se ha señalado, la terminación del contrato por aplicación de la causa de necesidades de la empresa, genera la obligación legal de pagar una indemnización por años de servicios y que corresponde a la indemnización por antigüedad, la que el empleador podrá imputar en la parte que corresponde al aporte efectuado a la cuenta de cesantía (Ley $N^{\circ} 19.728,2001$, art. 13). Lo que diferencia a esta causa de necesidades de la empresa de los otros supuestos que origina tal indemnización, es que su aplicación constituye una oferta irrevocable de pago de tal indemnización.

En efecto, desde el restablecimiento de esta causa de necesidades de la empresa —en el año 1990—, el legislador estableció un efecto especial a la comunica- 
ción a través de la carta de despido (Ley № 19.010, 1990, art. 4, inc. 4, en relación con el Código del Trabajo, 2003, art. 162, inc. 4), en cuanto ésta "supondrá una oferta irrevocable de pago de indemnización por años de servicios y de la sustitutiva de aviso previo, en caso de que éste no se haya dado..."(Ley N 19.010, 1990, art. 11, inc. 1, en relación con el Código del Trabajo, 2003, art. 169, inc. 1), estableciendo la acción para el pago inmediato de las sumas correspondientes (Ley $\mathrm{N}^{\circ} 19.010,1990$, art. 11, inc. 2, en relación con el Código del Trabajo, 2003, art. 169, inc. 2) y, ciertamente, reconociendo también la acción para la impugnación de dicha causal (Ley № 19.010, 1990, art. 11, b, inc. 4, en relación con el Código del Trabajo, 2003, art. 169, b). Sin embargo el texto original, establecido por la Ley 19.010 (1990), restringió la impugnación de tal causa a la condición de que el trabajador no hubiese recibido ni total ni parcialmente las indemnizaciones debidas, o que las hubiese reclamado judicialmente, toda vez que ello significaría la aceptación de la causal, tal como lo establecía la Ley N¹9.010, "El hecho de que el trabajador reciba parcial o totalmente este pago o inste por él del modo previsto en el inciso anterior, importará la aceptación de la causal, sin perjuicio de su derecho a reclamar las diferencias que estime que se le adeuden..." (1990, art. 11, a, inc. 3). Ciertamente que dicha exigencia afectó el reclamo judicial y, tal vez por ello, se desarrolló en dicho período una escasa jurisprudencia sobre la configuración de esta causa y de sus efectos.

Pero diez años después, la Ley $N^{\circ} 19.759$ (2001) modificó el régimen jurídico de la oferta irrevocable de la indemnización, tanto en lo que se refiere a la obligación de su pago inmediato, respecto de lo que se establecieron algunas medidas para garantizar dicho pago ${ }^{14}$, como en relación a los efectos de la recepción o reclamo de las indemnizaciones, en cuanto ello no significaría la aceptación de la causa de necesidades de la empresa.

Precisamente, ha sido sobre esta última materia en donde se ha presentado un mayor debate jurisprudencial. En primer lugar, si la acción para el pago de las indemnizaciones requiere la previa aceptación de la oferta de la indemnización. En segundo término, si procede la impugnación judicial de la causa de necesidades de la empresa, después de haber aceptado las indemnizaciones que proceden por la aplicación de dicha causa. En tercer lugar, si procede la impugnación de tal causa, si el trabajador ha suscrito el respectivo finiquito.

En primer lugar, se ha discutido si la acción para el pago de las indemnizaciones establecida en el Código del Trabajo, (2003, art. 169, a) requiere la previa aceptación de la propuesta de la carta de despido. Sin embargo, la doctrina jurisprudencial

\footnotetext{
${ }^{14} \mathrm{Al}$ respecto se establecieron dos medidas: De una parte, estableció la obligación del empleador, de pagar la indemnización en un solo acto al momento de extender el finiquito (Código del Trabajo, 2003, art. 169, a, inc. 2.), aunque trabajador y empleador pueden acordar fraccionar dicho pago y, en todo caso, dicho acuerdo debe ser ratificado ante la Inspección del Trabajo. De la otra, si el empleador no paga la indemnización, el trabajador puede accionar judicialmente a través de procedimiento ejecutivo, bastando como título la carta de aviso (Código del Trabajo, 2003, art. 169, a, inc. 4).
} 
sostiene actualmente que la calidad de irrevocable se adquiere "...por el solo ministerio de la ley, sin que sea presupuesto de la misma, la aceptación del trabajador ..." (Vergara con AFP Pro Vida S.A., 2016, cons. 7).

Respecto de la procedencia de la impugnación de dicha causa en el caso de haber recibido el todo o parte de la indemnización, se han planteado dos posiciones. Primera, la que rechaza procedencia de la acción, en cuanto el texto legal exigiría del trabajador "...no haber hecho aceptación de ella, del modo previsto en el número anterior" (Rivera con Empresa de Abastecimiento de Zonas Aisladas, 2011, cons. 2; Citando al Código del Trabajo, 2003, art. 169, b). Segunda, la que plantea la plena procedencia de dicha acción judicial, en cuanto la condición planteada ha sido expresamente derogada por Ley N 19.759 de 2001 (Tal como planteo tempranamente en Rojas González Juan Pablo con Colegio de la Santísima Trinidad S.A, 2007) y, además, es coherente con la intención del legislador en un análisis histórico: permitir al trabajador suscribir el finiquito y recibir las indemnizaciones y, conjuntamente, accionar ante los tribunales para impugnar la causal. Cabe indicar que en la actualidad, la Corte Suprema concluye en la plena procedencia de la acción en tal supuesto, en base a los fundamentos señalados (Vergara con AFP Pro Vida S.A., 2016; Varas con París Administradora Ltda., 2017).

En tercer lugar, y respecto a la procedencia de la acción por impugnación de dicha causa en el supuesto que haya celebrado un finiquito, la doctrina jurisprudencial plantea una evolución en razón del poder liberatorio que tenga el finiquito. Así, unos años atrás, se reconocía que el finiquito convenido otorgaba poder liberatorio general, planteándose la validez de las reservas a derechos y acciones especificados (En ese sentido: Rivera con Empresa de Abastecimiento de Zonas Aisladas, 2011), por consiguiente las reservas que se hicieran debían ser concretas, exigiéndose incluso que debía entonces definirse la concreta acción de impugnación de la causa de necesidades de la empresa (Palomo con Fundación Nacional del Comercio para la Educación, 2013).

Sin embargo, la actual doctrina jurisprudencial ha definido que el poder liberatorio del finiquito está referido a los derechos y acciones que se señalen, y respecto de las concretas materias que se acuerden:

... el poder liberatorio se restringe a todo aquello en que las partes han concordado no se extiende a los aspectos en que no se formó, sea porque una de las partes formula la reserva correspondiente, sea porque se trate de derechos u obligaciones no especificados por los comparecientes, sea por cualesquiera otras razones que el entendimiento humano pudiera abarcar. (María Palomo Fuentes y otros con Fundación Nacional del Comercio para la Educación, 2015, cons. 11) 
$Y$ ello tiene un fundamento normativo claro: Primero, al tratarse de un finiquito en materia laboral, recae sobre normas de orden público, "... exige la especificación concreta y expresa de los bienes jurídicos de los cuales se dispone..." (Olivieri con Inversiones Inmazzo Ltda., 2017, cons. 10). Segundo, dado que el finiquito tiene naturaleza transaccional, "rige (...) lo dispuesto en artículo 2446 del Código Civil, (...) por la cual es indispensable requerir la máxima claridad en cuanto a los derecho, obligaciones, prestaciones, indemnizaciones que comprende..." (Olivieri con Inversiones Inmazzo Ltda., 2017, cons. 10; En el mismo sentido; Varas con Geovitta S.A, 2016, inc. 7).

\subsubsection{La impugnación de la causa, su cambio de calificación y las indemnizacio- nes por término de contrato}

Pues bien, la causa de necesidades de la empresa puede ser objeto de impugnación judicial, para lo cual la norma legal remite a la acción judicial de despido injustificado, indebido o improcedente, en conformidad al Código del Trabajo (2003, art. 168).

Si el juez declara el despido como improcedente — dada su falta de acreditación por parte del empleador-, el acto de terminación del contrato de trabajo cambia de calificación, configurándose al efecto un "despido injustificado"15, con los respectivos efectos jurídicos que se establecen, estos son de la indemnización sanción por despido injustificado y el de la improcedencia de imputación de los aportes empresariales del seguro de cesantía a la indemnización por antigüedad.

Así, el primer efecto es el del nacimiento de una indemnización sancionatoria por el despido injustificado (según su fundamento jurídico es, precisamente, la sanción al empleador por haber incurrido en una terminación del contrato sin fundamento legal, en este sentido, véase: Rojas Miño Irene, 2013), cuyo monto se define en base a indemnización por antigüedad y la causa imputada por el empleador o incumplimiento de las formalidades del despido, en conformidad al Código del Trabajo (2003, art. 168, inc. 1).; correspondiendo en caso de despido improcedente de necesidades de la empresa a un $30 \%$ de la indemnización por antigüedad.

El segundo efecto, es el de la improcedencia de imputación de los aportes empresariales del seguro de cesantía a la indemnización por antigüedad ${ }^{16}$, toda vez

\footnotetext{
${ }^{15}$ Si bien es claro y definitivo el cambio de calificación, el problema se ha planteada con algunos de los demás supuestos de despido injustificado, en cuanto se mantendría una ficción legal. Sin embargo, el legislador no reconoce en definitiva la configuración de un despido injustificado, en cuanto que por una "ficción legal" establece que la terminación del contrato ha sido por alguna de las causas del artículo 161 del Código del Trabajo de 2003, es decir, por necesidades de la empresa o desahucio empresarial.

${ }^{16}$ En este sentido debe recordarse que la Ley 19.728 (2001), estableció un seguro de desempleo, que será financiado por los fondos de la cuenta individual de cada trabajador, salvo que proceda también el fondo solidario. Pues bien, la cuenta individual es financiada en parte por el trabajador (a través de una cotización mensual equivalente al $0,6 \%$ de su remuneración con contrato indefinido) y en parte 
que ella procede cuando su origen es la causa de necesidades de la empresa, tal como lo plantea la Ley N ${ }^{\circ}$ 19.728: "Se imputará a esta prestación la parte del saldo de la Cuenta Individual por Cesantía constituida por las cotizaciones efectuadas por el empleador más su rentabilidad, deducidos los costos de administración que correspondan..." (2001, art. 13, inc. $\left.2^{\circ}\right)$, y no la del despido injustificado. Si bien, esta conclusión ha sido objeto de discusión en la jurisprudencia, en los últimos años reiteradas sentencias pronunciadas en recursos de unificación de jurisprudencia han llegado a tal conclusión, sosteniendo al efecto que "... deba entenderse que la sentencia que declara injustificado el despido por necesidades de la empresa priva de base a la aplicación del inciso segundo del artículo 13 de la ley ya tantas veces citadas" (González con LATAM Airlines Group S.A., 2017, cons 3).

\section{Conclusiones}

Es cierto que la terminación del contrato de trabajo, constituye una institución jurídica laboral respecto de la que se plantea una mayor divergencia entre trabajadores y empresarios, y ello en razón de la contradicción de intereses que en ella se plantea; el reclamo de la estabilidad laboral por parte de los primeros, versus la flexibilidad empresarial por los segundos. Y en la actualidad, en el caso chileno, esta discordancia se presenta principalmente respecto de vigencia de la causa de necesidades económicas de la empresa, aunque hasta décadas atrás se planteaba de igual manera en relación al desahucio empresarial.

En primer lugar, se constata que el restablecimiento de esta causa de necesidades de la empresa en el sistema jurídico chileno, fue efectuada sin atender a las normas y recomendaciones tanto de Derecho Internacional como de Derecho Comparado, que establecen de una parte al necesario deber de las empresas de informar a los trabajadores y de consultar a los representantes de los mismos sobre la aplicación de estas medidas y, de la otra, al establecimiento de procedimientos administrativos ante los despidos colectivos.

En segundo término, respecto de esta causa que se plantean las interrogantes formuladas y desde las dos perspectivas señaladas. De una parte, en qué medida el régimen jurídico del sistema de terminación del contrato de trabajo permite que la causa de necesidades de la empresa reemplace al de desahucio empresarial. Y, de la otra, en qué medida, la configuración de dicha causa plantea tal nivel de exigencias que hace ineficaz su aplicación.

Es cierto que el sistema de terminación del contrato de trabajo actualmente vigente constituye formalmente un sistema causado, y que el desahucio empresarial ha sido excluido como causa a tal fin, salvo específicas excepciones. Pero también es 
cierto que el despido, como decisión empresarial, se impone en dicha terminación del contrato, aun cuando no esté fundado en causa alguna, por lo que se constituye como desahucio empresarial.

En efecto, el despido empresarial sin fundamento procedería al interior de tal sistema, salvo en especiales supuestos de protección de la estabilidad laboral en los que se configura el despido nulo por incumplimiento de las exigencias establecidas. En los demás casos, el efecto de este despido sin causa es el pago de las indemnizaciones establecidas, la de antigüedad, cuyo monto es similar cualquiera sea la causa, y la sancionatoria, cuyo monto difiere según cual sea la causal alegada. Pero precisamente, es la de necesidades de la empresa la que tiene un menor monto asignado. Por consiguiente, en un despido sin causa, el aplicar la de las necesidades de la empresa significa un menor costo monetario para el empleador.

De otra parte, es cierto que la configuración de la causa de necesidades de la empresa ha sido definida por la doctrina jurisprudencial, particularmente por la Corte Suprema, la que también ha completado el régimen jurídico de la aplicación de esta causa. De esta manera, se reitera la práctica de los sistemas comparados que definen expresamente esta causa, tal como son Francia y Alemania, en los que la jurisprudencia ha sido quien ha definido el contenido y alcance de esta causa de terminación del contrato de trabajo. Ciertamente, que este común comportamiento responde a que la definición legal de dicha causa constituye concepto jurídico indeterminado, por lo que ha correspondido a la jurisprudencia definir dicho contenido y alcance, a fin de operar con mayores niveles de seguridad jurídica.

Al efecto, la Corte Suprema plantea que la causa de necesidad de la empresa debe fundarse en un supuesto técnico o económico, que tal necesidad sea de carácter objetivo y que haya una relación causal entre ésta y la necesaria separación de uno más trabajadores. $Y$ ha sido este mismo tribunal, junto a las cortes de apelaciones y los juzgados del trabajo, los que han desarrollado esta doctrina.

Afirmar que la definición efectuada por tal doctrina haya quitado eficacia a dicha causa de necesidades de la empresa es improcedente, pues los conceptos jurídicos deben tener un contenido y este debe ser definido, en este caso por los mismos tribunales de justicia. Ciertamente que lo que plantea esta doctrina y, a su vez, refuta la crítica planteada por algunos sectores, es que la definición de la causa de terminación del contrato debe operar a estándares objetivos y no a la concepción del empleador de los que constituya la necesidad de la empresa, debate que en definitiva envuelve a todo el Derecho del Trabajo, desde sus orígenes hasta el presente, y este es quién define las reglas en el ámbito de las relaciones laborales. De una parte se ha reclamado que sean los empleadores, en virtud del derecho de propiedad o en el del principio de la autonomía individual; de la otra, se plantea que en virtud de los 
bienes jurídicos superiores que están involucrados, estas reglas deben establecerse por el Estado o por la autonomía colectiva.

\section{Referencias Bibliográficas}

Aladino Póntigo Mancuan y otros con Lan Cargo S.A., Rol N 963-2015 (Corte de Apelaciones de Santiago 2 de septiembre de 2015). Recuperado de https://westlawchile.cl id: CL/JUR/5594/2015

Alba Rita Maldonado Hernández contra Empresa de Correos, Rol N 8032-2004 (Corte de Apelaciones de Santiago 28 de septiembre de 2005). Recuperado de https://westlawchile.cl id: CL/JUR/1118/2005

Álvarez del Cuvillo, A. (2009). Informe sobre la regulación del despido en Europa. Temas laborales, (99), 259-297. Recuperado de https://bit.ly/30ZClzR

Arce Ortiz, E. (2013). Derecho individual del trabajo en el Perú: Desafíos y deficiencias (2a ed.). Lima: Palestra.

Ávila y otra con Fundación Educacional Padre Alberto Hurtado, Rol N 54-2014 (Corte de Apelaciones de Chillán 1 de agosto de 2014). Recuperado de https://bit.ly/2DSzOAI

Blas Morales, J. (1990) La estabilidad en el empleo y la terminación del contrato de trabajo. Revista jurídica del trabajo.

Blasco Pellicer, A., (2012). La extinción del contrato por voluntad del empresario. En L. M. Camps Ruiz, J. M. Ramírez Martínez, \& C. L. Alfonso Mellado (Coords.), Derecho del trabajo (2nd ed.). Valencia: Tirant lo Blanch.

Bustos Muñoz, F., (2013). El Término de contrato por la causal de necesidades de la empresa. Su contenido esencial y su interpretación jurisprudencial en el ordenamiento laboral chileno. Tesis de Magíster. Universidad de Talca.

Claudia Alejandra Fernández Pino con Empresas La Polar S.A., Rol N 174-2016 (Corte de Apelaciones de Concepción 5 de agosto de 2016). Recuperado de https://bit.ly/3kTo8mu

Code du Travail. Légifrance, Paris, Francia, 01 de marzo de 2008. Recuperado de https://bit.ly/30LEh5K

Convenio $\mathrm{N}^{\circ}$ 158. Sobre la terminación de la relación de trabajo, 1982. Organización Internacional del Trabajo, 23 de junio de 1982. Recuperado de https://bit.ly/2DxtoM5 
Las necesidades de la empresa como causa de terminación del contrato de trabajo...

Correa con Caja de Compensación de Asignación Familiar de los Andes, Rol N $1792-$ 2015 (Corte de Apelaciones de Santiago 5 de febrero de 2016). Recuperado de https://bit.ly/3ayNQIb

Cortes Bordones Jorge con AMECO Chile S.A., Rol N 78-2014 (Corte de Apelaciones de La Serena 8 de septiembre de 2014). Recuperado de https://bit.ly/2Yd4x74

Cruz Villalón, J. (2012). La intervención de la unión europea en materia de despido. En su: La regulación del despido en Europa. Régimen formal y efectividad práctica. Valencia: Tirant lo Blanch.

Decreto con Fuerza Ley $\mathrm{N}^{\circ} 1$. Fija el texto refundido, coordinado y sistematizado del Código del Trabajo. Diario Oficial de la República de Chile, Santiago, Chile, 16 de enero de 2003. Recuperado de http://bcn.cl/2f6o9

Decreto con Fuerza de Ley $N^{\circ}$ 178. Código del Trabajo. Diario Oficial de la República de Chile, Santiago, Chile, 28 de mayo de 1931. Recuperado de http://bcn.cl/2fzqt

Decreto Ley $\mathrm{N}^{\circ}$ 2.200. Fija normas relativas al contrato de trabajo y a la protección de los trabajadores. Diario Oficial de la República de Chile, Santiago, Chile, 15 de junio de 1978. Recuperado de http://bcn.cl/2fznt

Desdentado Bonete, A. (2011). Introducción a un debate. Los despidos económicos en España: El sistema su crisis y los límites de su reforma. En su: Despido y crisis económica. Los despidos económicos tras la reforma laboral. Un análisis desde el derecho y la economía. Valladolid: Lex Nova.

Díaz, V., y De Salvo, C. (2013). La extinción de la relación por fuerza mayor o falta o disminución de trabajo no imputable al empleador. En H. O. García, C. S. Virgili, y N. Barcos, Relación de trabajo (Vol. 4). Buenos Aires: Ediar.

Dirección del Trabajo. (2009). Inequidades y brechas de género en el empleo. Análisis de los resultados de la Encuesta Nacional de Coyuntura Laboral Encla 2008, Sexta Versión. Santiago, Departamento de Estudios. Recuperado de https://bit.ly/30UgSPq

Dirección del Trabajo. (2012). Encla 2011. Informe de resultados, séptima encuesta laboral. Santiago: Departamento de Estudios. Recuperado de https://bit.ly/2CqC5ad

Dirección del Trabajo. (2015). Encla 2014. Informe de resultados octava encuesta laboral (2a ed.).Santiago: Departamento de Estudios. Recuperado de https://bit.ly/3kHQhgq

Directiva N 98/59/CE. Consejo de 20 de julio de 1998. relativa a la aproximación de las legislaciones de los Estados miembros que se refieren a los despidos colectivos. Diario Oficial de las Comunidades Europeas, 12 de agosto de 1998. Recuperado de https://bit.ly/2DR7KSA 
Fainguenblat, L. (2008). Fuerza Mayor. En M. Ackerman (Dir.), Extinción de la relación laboral (pp. 247-270). Buenos Aires: Rubinzal - Culzoni.

Fernández Cuervo, J. A. (2014). Efectos de la omisión de los hechos en la carta de despido. Estudios laborales, (9), 39-98.

Fuentes con Inmobiliaria Parque y Jardines del Sendero S.A., Rol N 609-2010 (Corte de Apelaciones de Santiago 16 de agosto de 2010). Recuperado de https://bit.ly/3g4100X

Gajardo con Market Line Chile S.A., Rol N 1391-2014 (Corte de Apelaciones de Santiago 10 de febrero de 2015). Recuperado de https://westlawchile.cl id: $\mathrm{CL} / J U R / 768 / 2015$

Gamonal Contreras, S., y Guidi Moggia, C. (2015). Manual del contrato de trabajo. Santiago: Thomson Reuters.

González con LATAM Airlines Group S.A., Rol N³3969-2016 (Corte Suprema 24 de enero de 2017). Recuperado de https://bit.ly/2Eirpv6

Hernández Bejarano, M. (2012). La regulación del despido en Europa. Régimen formal y efectividad práctica. En J. Cruz Villalón (Ed.), La regulación del despido por causas económicas en Francia. Valencia: Tirant lo Blanch.

Historia del Artículo 10 de la Ley N 19.010. Derecho a reclamar judicialmente. Biblioteca del Congreso Nacional de Chile, 13 de julio de 1990. Recuperado de http://s.bcn.cl/2flkq

Historia de Ley N 7.747. Sesiones de la Cámara de Diputados -ordinaria-1943. Mensaje del Presidente de la República, D. Juan Antonio Ríos, en Mensaje de Ejecutivo (Vol. 1).

Hormazábal con Comercial Kaufmann S.A., Rol No 1297-2014 (Corte de Apelaciones de Santiago 8 de enero de 2015). Recuperado de https://bit.ly/3hi2fLm

Juan Pérez Campo con Latam Airlines Group S.A., Rol N 4881-2015 (Corte Suprema 31 de diciembre de 2015). Recuperado de https://westlawchile.cl id: $\mathrm{CL} / \mathrm{JUR} / 8172 / 2015$

Lecaros Sánchez, J. M. (1991). La causal de despido necesidades de la empresa. Revista jurídica del trabajo, (559), 29-35.

León con Zeal Sociedad Concesionaria S.A., Rol N 437-2015 (Corte de Apelaciones de Valparaíso 14 de diciembre de 2015). Recuperado de https://bit.ly/3kBViqM

Ley $\mathrm{N}^{\circ} 16.455$. Normas para la terminación del contrato de trabajo. Diario Oficial de la República de Chile, Santiago, Chile, 06 de abril de 1966. Recuperado de http://bcn.cl/2fz06 
Las necesidades de la empresa como causa de terminación del contrato de trabajo...

Ley $N^{\circ}$ 18.018. Modifica decreto Ley № 2.200 de 1978, y otras disposiciones en materia laboral. Diario Oficial de la República de Chile, Santiago, Chile, 14 de agosto de 1981 Recuperado de http://bcn.cl/2fztv

Ley N ${ }^{\circ}$ 18.620. Código del Trabajo. Diario Oficial de la República de Chile, Santiago, Chile, 06 de julio 1987. Recuperado de http://bcn.cl/2fzym

Ley N 18.372. Modifica el Decreto Ley N².200, de 1978. Diario Oficial de la República de Chile, Santiago, Chile, 17 de diciembre de 1984. Recuperado de http://bcn.cl/2fz62

Ley $N^{\circ} 19.010$. Establece normas sobre terminación del contrato de trabajo y estabilidad en el empleo. Diario Oficial de la República de Chile, Santiago, Chile, 29 de noviembre de 1990. Recuperado de http://bcn.cl/2flk2

Ley $\mathrm{N}^{\circ}$ 19.631. Impone obligación de pago de cotizaciones previsionales atrasadas como requisito previo al término de la relación laboral por parte del empleador. Diario Oficial de la República de Chile, Santiago, Chile, 28 de septiembre de 1999. Recuperado de http://bcn.cl/2g0bw

Ley $N^{\circ}$ 19.728. Establece un seguro de desempleo. Diario Oficial de la República de Chile, Santiago, Chile, 14 de mayo de 2001. Recuperado de http://bcn.cl/2fa5x

Ley $N^{\circ}$ 19.759. Modifica el Código del Trabajo en lo relativo a las nuevas modalidades de contratación, al derecho de sindicación, a los derechos fundamentales del trabajador y a otras materias que indica. Diario Oficial de la República de Chile, Santiago, Chile, 05 de octubre de 2001. Recuperado de http://bcn.cl/2fzdj

Ley $N^{\circ}$ 20.087. Sustituye el procedimiento laboral contemplado en el libro V del Código del Trabajo. Diario Oficial de la República de Chile, Santiago, Chile, 03 de enero de 2006. Recuperado de http://bcn.cl/2g08z

Ley $\mathrm{N}^{\circ} 20.720$. Sustituye el régimen concursal vigente por una ley de reorganización y liquidación de empresas y personas, y perfecciona el rol de la superintendencia del ramo. Diario Oficial de la República de Chile, Santiago, Chile, 09 de enero de 2014. Recuperado de http://bcn.cl/2f81h

Ley N ${ }^{\circ}$ 20.744. Ley de Contrato de Trabajo. Boletín Oficial de la República Argentina, Buenos Aires, Argentina, 27 de septiembre de 1974. Recuperado de https://bit.ly/3gPgilq

Ley $N^{\circ}$ 24.013. Ley de empleo. Protección de trabajo. Boletín Oficial de la República Argentina, Buenos Aires, Argentina, 17 de diciembre de 1991. Recuperado de https://bit.ly/3gNfeEP 
Ley $\mathrm{N}^{\circ}$ 24.467. Marco regulatorio de la pequeña y mediana empresa. Boletín Oficial de la República Argentina, Buenos Aires, Argentina, 28 de marzo de 1995. Recuperado de https://bit.ly/2YJkORC

López López, J. (2007). La regulación del despido en el contexto europeo sobre el proceso de descontractualización de la relación laboral. Relaciones laborales, 1, 12211235.

López Terrada, E., y Nores Torres, L. (2011). La causalidad de los despidos económicos en el derecho comparado. En A. Desdentado Bonete, A. Puebla Pinilla, y S. Bentolila, Despido y crisis económica: Los despidos económicos tras la reforma laboral: Un análisis desde el derecho y la economía. Lex Nova: Valladolid.

Marcela Cordero Carvacho con Alo Ventas Limitada, Rol № 4884-2015 (Corte Suprema 6 de enero de 2016). Recuperado de https://westlawchile.cl id: CL/JUR/157/2016

María Isabel Treuna Treuna con Ilustre Municipalidad de Los Ángeles, Rol No $555-$ 2007 (Corte de Apelaciones de Concepción 26 de diciembre de 2007). Recuperado de https://westlawchile.cl id: CL/JUR/3219/2007

María Palomo Fuentes y otros con Fundación Nacional del Comercio para la Educación, Rol N 5000-2014 (Corte Suprema 8 de enero de 2015). Recuperado de https://westlawchile.cl id: CL/JUR/24/2015

Mariela Contreras Lobos con Ilustre Municipalidad de La Granja, Rol N ${ }^{\circ} 135-2017$ (Corte de Apelaciones de San Miguel 8 de junio de 2017). Recuperado de https://bit.ly/3kTozxh

Montoya Ogalde Víctor y otro con Asociación Chilena de Seguridad Social, Rol N ${ }^{\circ}$ 7022-2009 (Corte Suprema 22 de diciembre de 2009). Recuperado de https://bit.ly/3kJ2MID

Morales con Viña San Rafael S.A., Rol N 58-2011 (Corte de Apelaciones de Talca 17 de mayo de 2011). Recuperado de https://bit.ly/3aCN9xQ

Muller, A. (2011) La legislación de protección del empleo a prueba de la crisis económica. Un examen global de la reglamentación de los despidos colectivos por razones económicas. Nota de Información de DIALOGUE, (3), 1-12. Recuperado de https://bit.ly/2Q68C8J

Olivieri con Inversiones Inmazzo Ltda., Rol N 6880-2017 (Corte Suprema 13 de septiembre de 2017). Recuperado de https://bit.ly/2DUYzkB

Palomo con Fundación Nacional del Comercio para la Educación, Rol N 156-2013 (Corte de Apelaciones de Talca 4 de noviembre de 2013). Recuperado de https://bit.ly/3h4h8ku 
Las necesidades de la empresa como causa de terminación del contrato de trabajo...

Pamela Montalba Cancino con Fundación Consejo de Defensa del Niño, Rol N ${ }^{\circ} 128-$ 2017 (Corte de Apelaciones de Concepción 27 de mayo de 2017). Recuperado de https://bit.ly/313AznW

Quezada Marín Raúl Domingo con Distribución, Logística y Servicios Limitada, Rol N ${ }^{\circ}$ 483-2010 (Corte Suprema 13 de mayo de 2010). Recuperado de https://bit.ly/33RpyYA

Ramos con Veloso, Rol N²75-2016 (Corte de Apelaciones de Antofagasta 13 de marzo de 2017). Recuperado de https://bit.ly/2DSJW1b

Ratificación del Convenio $\mathrm{N}^{\circ}$ 158. Sobre la terminación de la relación de trabajo, 1982. Organización Internacional del Trabajo, 23 de noviembre 1985. Recuperado de https://bit.ly/2XNErr3

Recomendación $\mathrm{N}^{\circ}$ 119. Sobre la terminación de la relación de trabajo, 1963. Organización Internacional del Trabajo, 26 de junio de 1963. Recuperado de https://bit.ly/2PGItOP

Recomendación $\mathrm{N}^{\circ}$ 166. Sobre la terminación de la relación de trabajo, 1982. Organización Internacional del Trabajo, 22 de junio de 1982. Recuperado de https://bit.ly/3kHCExQ

Rivera con Empresa de Abastecimiento de Zonas Aisladas, Rol N 85-2011 (Corte de Apelaciones de Santiago 21 de septiembre de 2011). Recuperado de https://bit.ly/2EaHP8C

Rodrigo Mauricio Polo Ahern con Nova Austral S.A., Rol N²8-2007 (Corte de Apelaciones de Punta Arenas 26 de octubre de 2007). Recuperado de https://westlawchile.cl id:CL/JUR/7085/2007

Rojas González Juan Pablo con Colegio de la Santísima Trinidad S.A., Rol N 539-2007 (Corte de Apelaciones de Concepción 8 de noviembre de 2007). Recuperado de https://westlawchile.cl id:CL/JUR/2450/2007

Rojas Miño, I. (2015). Derecho del trabajo. Derecho individua del tabajo. Santiago: Thomson Reuters.

Rojas Miño, I. (2013). La naturaleza jurídica de la indemnización por término de contrato de trabajo en el ordenamiento laboral chileno. Revista de Derecho (Valparaíso), (41), 107-143. doi: 10.4067/s0718-68512013000200004

Romero Guggisberg, M. (1990). Las necesidades de la empresa en la Ley 19.010. Revista de Derecho (Concepción), 58(187), 117-126. Recuperado de https://bit.ly/3gyzJFa 
Rybertt Thennet Mónica M con Corporación de Televisión de la Pontificia Universidad Católica de Chile, Rol N 1638-2007 (Corte de Apelaciones de Santiago 3 de marzo de 2008). Recuperado de https://westlawchile.cl id: CL/JUR/462/2008

Tapia Guerrero, F., y Walker Errázuriz. F. (1990). Comentarios sobre proyecto de Ley de terminación del contrato de trabajo y estabilidad en el empleo. Revista jurídica del trabajo, (6), 77-84.

Thayer Arteaga, W., y Novoa Fuenzalida, P. (2015). Manual de derecho del trabajo. Derecho individual del trabajo (6 $6^{\mathrm{a}}$ ed., Vol. 4, Colección Manuales Jurídicos). Santiago: Jurídica de Chile.

Varas Castillo, M. (2011). Pérdida de eficacia de la causal de necesidades de la empresa en el sistema de terminación del contrato de trabajo. Revista chilena de derecho del trabajo y de la seguridad social (En línea), 2(3), 79-95. doi: 10.5354/07197551.2016.42927

Varas con Geovitta S.A., Rol N 6764-2015 (Corte Suprema 16 de marzo de 2016). Recuperado de https://westlawchile.cl id:CL/JUR/1796/2016

Varas con París Administradora Ltda., Rol N 40558-2016 (Corte Suprema 10 de enero de 2017). Recuperado de https://westlawchile.cl CL/JUR/646/2017

Vergara con AFP Pro Vida S.A., Rol N² 27170-2015 (Corte Suprema 9 de agosto de 2016). Recuperado de https://bit.ly/34aotvb

Walker Errázuriz, F. (1990). Reflexiones acerca de la estabilidad laboral. Revista jurídica del trabajo.

Yáñez Monje, E. (2010). Las necesidades de la empresa como causal de término de contrato ¿Conversión a un sistema de libre despido?. Revista chilena de derecho del trabajo y de la seguridad social (En línea), 1(1), 145-152. doi: 10.5354/07197551.2016 .43019

Zachert, U. (1998). Lecciones de derecho del trabajo alemán. Madrid: Ministerio de Trabajo y Asuntos Sociales.

\section{Para citar este artículo bajo Norma APA 6a ed. Rojas Miño, I. (2020). Las necesidades de la empresa como causa de terminación del contrato de trabajo en el sistema jurídico chileno Revista de Derecho (Coquimbo. En línea), 27, e4424, https://doi.org/10.22199/issn.0718-9753-2020-0013}

Copyright del artículo: @2020 Irene Rojas

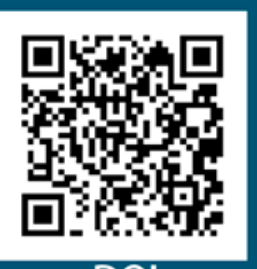

DOI

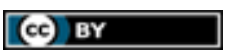

Este es un artículo de acceso abierto, bajo licencia Creative Commons BY 4.0. 